\title{
MEMORIA Y LINAJE EN LOS TEXTOS JURÍDICOS: LA ICO- NOGRAFÍA DE LOS ÁRBOLES DE CONSANGUINIDAD Y AFINIDAD EN LAS SIETE PARTIDAS
}

\author{
Jorge Prádanos Fernández \\ Universidad Complutense de Madrid
}

Resumen: Los árboles de consanguinidad y afinidad son unos tipos de iconografías jurídicas muy comunes y ampliamente difundidas en obras legales medievales, ya que ofrecen de forma clara y concisa las distintas reglas de parentesco y casamiento entre los diferentes individuos de una familia. Las Siete Partidas, como obra fundamental de las producciones jurídicas bajomedievales castellanas, también presentan dichas reglas de consanguinidad. En el presente artículo expongo los diversos ejemplos de esta iconografía en los manuscritos conservados, recalcando cómo este tipo iconográfico permanecerá en ediciones impresas posteriores de las Siete Partidas.

Palabras clave: Árbol, parentesco, consanguinidad, Siete Partidas, matrimonio, afinidad, iconografía.

MEMORY AND LINEAGE IN LEGAL TEXTS: THE ICONOGRAPHY OF CONSANGUINITY AND AFFINITY TREES IN THE SIETE PARTIDAS

Abstract: The consanguinity and affinity trees are a legal iconographic type very common and diffused in medieval legal works, because they offer clearly and concisely the diverse rules of parentesco and marriage between different persons of a family. The Siete Partidas as the fundamental work of the low medieval legal Castilian productions, also offer the mentioned rules of consanguinity. In the present essay I expose the diverse examples of this iconography in the conserved manuscripts, remarking how this iconographical type will remain in posterior printed editions of the Siete Partidas.

Key words: Tree, parentesco, consanguinity, Siete Partidas, marriage, affinity, iconography.

\footnotetext{
*Entregado: 15/05/2018. Aceptación definitiva: 24/10/2018.
} 


\section{INTRODUCCIÓN: EL ÁRBOL DE CONSANGUINIDAD Y AFINIDAD COMO REPRESENTACIÓN} ICÓNICA

El árbol de consanguinidad es una de las iconografías jurídicas más extendidas en los manuscritos medievales ${ }^{1}$. Es un tipo de diagrama que muestra de forma esquemática los grados de parentesco que existen entre los diferentes individuos de una unidad familiar. El interés por los lazos familiares fue una constante dentro del pensamiento de la Europa occidental medieval, tema que hunde sus raíces precisamente en el interés de la familia, de la gens, en la Antigua Roma². En un primer momento se recogieron listados de los diversos grados de parentesco en obras jurídicas medievales o en el propio texto bíblico. Sin embargo, con el objetivo de poder sintetizar esta información de forma clara y precisa, surgieron esquemas gráficos que pretendían clarificar y ordenar las diferentes relaciones existentes entre los miembros de una familia, desde los más cercanos hasta los más alejados, dando lugar a este tipo de iconografía jurídica ${ }^{3}$. Algunas copias del Corpus Iuris Canonici ${ }^{4}$, especialmente en las Decretales de Gregorio IX, texto que recoge precisamente los diferentes grados de afinidad y parentesco entre los individuos de una familia, contemplaron ya la posibilidad de reflejar de manera sintética las diversas relaciones de sangre en una imagen ${ }^{5}$. No obstante, esta tradición iconográfica aparece ya en obras de la Antigüedad Tardía como en la Notitia Dignitatum ${ }^{6}$, en el Breviario de

\footnotetext{
${ }^{1}$ Las principales obras de referencia son: VOLTERRA, E., «La "Graduum Agnationis Vetustissima descriptio" Segnalata da Cuias», Atti della Academia Nazionale dei Lincei, memorie, classe di Scienzia morali, storiche e filologiche, ser. 8, vol. 28, fasc. 1, Roma, 1978; LADNER, G. B., «Medieval and Modern Understanding of Symbolism: a comparison», Speculum, 54, (1979), pp. 241-250; PATLAGEAN, E., «Une représentation Byzantine de la parenté et ses origines occidentales», L'Homme, 6-4, (1966), pp. 59-81; SCHADT, H., Die Darstellungen der Arbores Consanguinitatis und der Arbores affinitatis, Tübingen, 1982. Klapisc-Zuber, C., Segalen, M., Zonabend, F., Historia de la familia, t. 1, Alianza, Madrid, 1998, $2^{a}$ ed.; MENÉNDEZ PIDAL, F., La nobleza en España: ideas, estructuras, historia, Fundación Cultural de la Nobleza Española, Madrid, 2008, $1^{\text {a }}$ ed., pp. 47-49; NOGALES RinCón, D., «Cultura visual y genealogía en la corte regia de Castilla durante la segunda mitad del siglo XV», E-Spania, 11, junio de 2011, http://journals.openedition.org/e-spania/20362, consultado el 24 de octubre de 2018.

${ }^{2}$ Para el estudio de la historia de la familia es fundamental la obra de BuRGUIÈRE, A., KLAPISC-ZUBER, C., Segalen, M., Zonabend, F, Historia de la familia, 1; KlaPisC-Zuber, C., L'ombre des ancêtres. Essai sur l'imaginaire médiéval de la parenté, Fayard, París, 2000, 1ª ed.

${ }^{3}$ MARTínez de Aguirre AldAZ, J., «En torno a la iconografía de la familia en el occidente medieval», La familia en la edad media: XI Semana de Estudios Medievales, Nájera, del 31 de julio al 4 de agosto de 2000, José Ignacio de la Iglesia (coord.), Instituto de Estudios Riojanos, Logroño, 2001, pp. 403-454.

${ }^{4}$ Con este nombre se agrupa a un conjunto de obras jurídicas surgidas entre los siglos XII al XIV que constituyeron el grueso del derecho de la Iglesia. Dicho cuerpo normativo estuvo conformado, en primer lugar, por el Concordia discordantium canonum o Decreto de Graciano (por ser este jurista del siglo XII su autor) que reunió cánones y fuentes anteriores y las armonizó mediante un método escolástico de preguntas e interpolaciones. En segundo lugar, el Liber Extra o Decretales de Gregorio IX, un conjunto de cinco libros redactados por San Raimundo de Peñafort hacia 1234 surgidas para paliar las contradicciones existentes por los diversos decretos emanados por papas como Alejandro III, Inocencio III o el mismo Gregorio IX. Por último, además de las obras citadas el código se completó con el Liber Sextus de Bonifacio VIII, el Liber Septimus o Constituciones de Clemente V y las Extravagantes de Juan XXII.

${ }^{5}$ L'Engle, S., GiBBS, R., Iluminating the Law. Medieval legal manuscripts in Cambridge collections, Brepols, Londres, 2001, $1^{\text {a }}$ ed., pp. 68-71.

${ }^{6}$ Fernández FernándeZ, L., RuIZ, E., Libro de las claves del Poder: Notitia Dignitatum. Ms. Reserva 36 de la Biblioteca Nacional de España, Milennium, Madrid, 2009, $1^{\text {a }}$ ed.
} 
Alarico $^{7}$, en las en las Instituciones de Justiniano o Etimologías de San Isidoro (por ejemplo, el manuscrito D.I.1 de la RBME) ${ }^{8}$. Este tema tuvo diversas formas de representación, primando la forma de árbol, pero también se utilizaron gráficos en forma de cruz e incluso se adoptaron configuraciones antropomórficas y arquitectónicas.

Por lo que respecta a la codificación visual de las relaciones de parentesco, se desarrollaron, prácticamente de forma simultánea dos tipos de esquema distintos que podían ser representados de forma separada o a veces de manera conjunta. El motivo conocido como árbol de consanguinidad es un esquema que desarrolla de forma visual los diversos grados de parentesco entre los individuos de una familia ordenados de forma ascendente, descendente y tangente según los grados de parentescos del derecho canónico o del romano, que difieren en algunos aspectos ya que el parentesco en el derecho romano se establecía hasta el sexto grado, mientras que en el derecho canónico se redujo al cuarto grado a partir del IV Concilio de Letrán. El árbol de afinidad, por otro lado, desarrolla de forma esquemática las posibles relaciones matrimoniales permitidas entre los individuos de una misma familia expresando de forma escrita en qué ocasiones está permitido el casamiento y en qué ocasiones está prohibido.

Según Martínez de Aguirre ${ }^{9}$ las diferentes tipologías de árboles de consanguinidad se pueden clasificar en cuatro grupos: árboles geométricos y crucíferos, árboles antropomórficos, árboles arquitectónicos y árboles mixtos. El primero de estos grupos, los árboles de tipo geométrico, es el más extendido por su aparente sencillez (Fig. 1). El esquema tiende por lo general a una forma geométrica sencilla, a veces en forma de tabla a veces en forma de cruz, e incluso existen árboles de tipo circular, como es el caso del Ms. latin. 4412 (ff. 76v-77v), o incluso romboidal como el Ms. latin. 4410 (ff. 4r-4v) ambos de la Biblioteca Nacional de Francia ${ }^{10}$. La forma crucífera es la más usual, primero por su funcionalidad al poder disponer de dos bandas principales, y segundo por su evidente carácter cristológico. Este tipo de representaciones cruciformes derivaron en una forma que acabó por convertirse en un auténtico árbol geometrizado, ya que las líneas secundarias superiores adoptaron una forma triangular que semejaba el perfil de la copa de un árbol.

La organización interna respondía a la distribución de las personas en casillas, bien rectangulares, bien circulares, siendo esta última la más usual, y en muchas ocasiones conectando los círculos mediante líneas de color. De este modo el tronco del árbol se destinaba a los individuos principales de las líneas ascendente y descendente del primer al cuarto grado. Existen también variaciones más heterodoxas de esta tipología, como distribuciones en zigzag como el que aparece en el Beato Morgan (Morgan Li-

\footnotetext{
${ }^{7}$ LADNER, G. B., «Medieval and Modern», p. 244.

${ }^{8}$ DE SILVA Y VerÁSTEGUI, S., «Contribución al estado de la cuestión de los estudios iconográficos en los manuscritos jurídicos ilustrados de la Edad Media», Scriptorium, 45, (1991), p. 91. Sobre el manuscrito: De Silva y VerÁstegui, S., Iconografía del siglo X en el reino de Pamplona-Nájera, Diputación Foral de Navarra, Pamplona, 1984, $1^{\text {a }}$ ed.

${ }^{9}$ Vid. MARTínez de AguiRre AldaZ, J., «En torno a la», p. 4.

${ }^{10}$ MARTíneZ De AguiRre AldAZ, J., «En torno a la», p. 5.
} 
brary, MS. M. 644, f. 237r) ${ }^{11}$. En los árboles de consanguinidad, los ancestros están colocados en la parte superior del esquema, lo que vendría a ser la copa del árbol, mientras que los progenitores del individuo se encuentran justo encima del tronco. Esta forma es coherente con la trasmisión de la descendencia, pero contradice la forma del árbol ya que los que originan la línea familiar no son los que están enraizados como sí sucede, por ejemplo, en la iconografía del árbol de Jesé ${ }^{12}$. En opinión de G. B. Ladner, es posible que esta ubicación tenga que ver con una concepción del árbol como un hombre-microcosmos invertido, con sus raíces en la cima simbolizando el Cielo ${ }^{13}$.

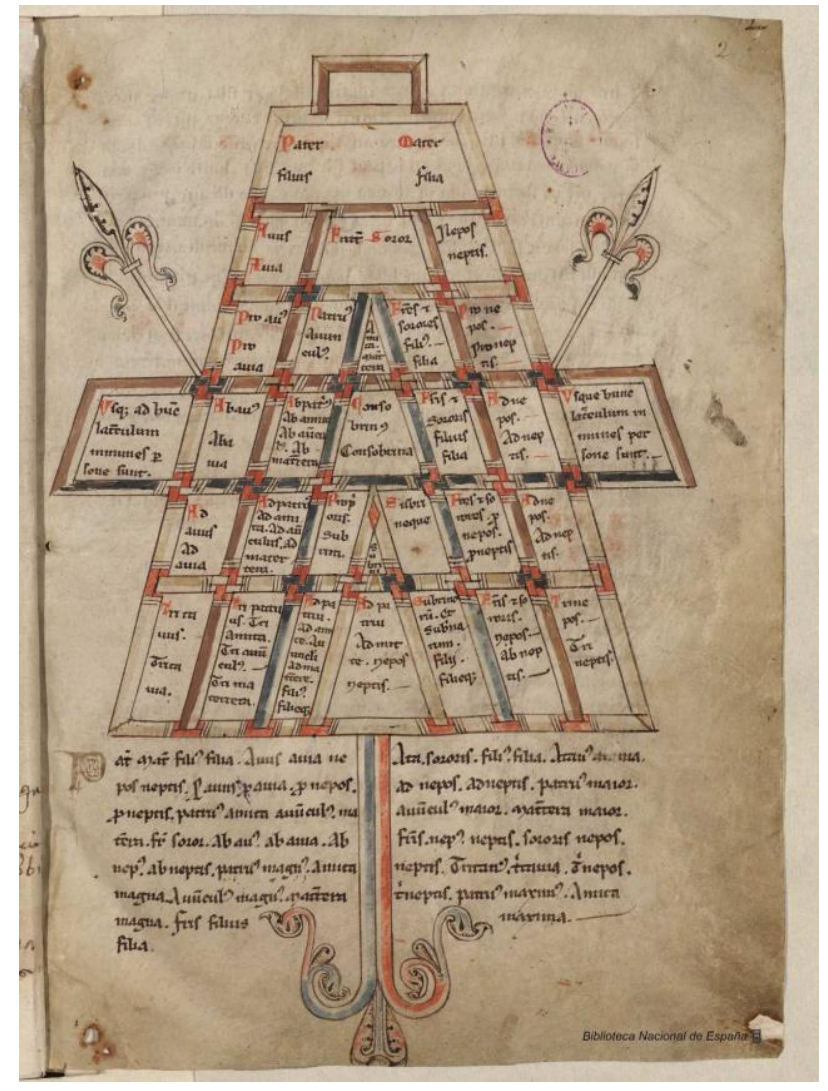

Figura1. Árbol de consanguinidad geométrico en forma de «A». Corpus Pelagianum s. XIII, BNE, MSS/ 1513, f. 2r.

\footnotetext{
${ }^{11}$ Sobre el Beato ver: WiLliams, J., The illustrated Beatus: a corpus of the illustrations of the commentary on the Apocalypse, Harvey Miller, Londres, 1994, $1^{\text {a }}$ ed., v. 3.

${ }^{12} \mathrm{El}$ árbol de Jesé es una iconografía cristiana que muestra la línea genealógica de Cristo en base a la profecía de Isaías, mediante la cual el Mesías tendría que proceder de la descendencia de Jesé (Isaías. 11, 1). En esta iconografía, es común encontrar a Jesé en la base del árbol, que es quién conforma la raíz del linaje del Salvador, y la Virgen con el Niño en la parte superior como descendientes de este. Un análisis sintético sobre la evolución iconográfica del árbol puede verse en MAZARBEITIA VALLE, S., «El Árbol de Jesé», Revista Digital de Iconografía Medieval, 1, (2009), pp. 1-8. Además, ver: RÉAU, L., Iconografía del arte cristiano, Ediciones del Serbal, Barcelona, 2000, $1^{\mathrm{a}}$ ed., t. 1, vol. 2, pp. 135-140. WATSON, A., The Early Iconography of the Tree of Jesse. Oxford University Press, Oxford, 1980, $1^{\mathrm{a}} \mathrm{ed}$.

${ }^{13}$ LADNER, G. B., «Medieval and Modern», p. 244.
} 
El siguiente grupo, el de los esquemas antropomórficos, está basado en el esquema crucífero-arbóreo anterior, pero con adiciones antropomórficas: cabeza, manos o pies; bien la adopción del esquema en el interior de una figura humana, o bien la figura humana como sostén del árbol (Fig 2.). El recurso de la figuración parece vincularse con la costumbre germánica de asimilar las relaciones familiares como partes del cuerpo humano $^{14}$; así el linaje principal se desarrolla desde la cabeza al resto del tronco, mientras que las ramas colaterales van alcanzando las extremidades. Esta figura antropomorfa, generalmente barbuda y anciana ${ }^{15}$, en el siglo XII aún no aparece coronada, aspecto que se modificará en el siglo XIII donde la figura sí aparecerá coronada y con un tratamiento mucho más vertical ${ }^{16}$. Estas composiciones en las que aparece la figura coronada podrían derivar de composiciones bizantinas de raigambre imperial: corona, vestimenta, insignias, etc., rememorando así la imagen del emperador Justiniano o Teodosio II apareciendo en muchos manuscritos del Decreta de Graciano y de las Decretales de Gregorio IX como el códice Rossianus. 595 de la Biblioteca Apostólica Vaticana, fechado hacia $1200^{17}$. Sin embargo, como ya se ha dicho con anterioridad, las representaciones antropomorfas más tempranas no tienen esta iconografía imperial ni este estilo tan «bizantinizante», como es el caso de muchas copias de las Etimologías ${ }^{18}$ del siglo X. No obstante, en muchos de estos manuscritos a la figura se le otorga una relación con la figura de Cristo: en ciertas ocasiones aparece con nimbo y nimbo crucífero como es el caso del manuscrito H 11 del St John's College de Cambridge. Pasado ya el siglo XIV podemos encontrar ejemplos en los que la imagen se asocia a la figura del pontífice, ampliando el repertorio del tema.

\footnotetext{
${ }^{14}$ MARTíneZ DE AGUiRRE AldAZ, J., «En torno a la», p. 9. El autor ve un precedente de esta disposición en el Libro de Kells en la página dedicada a San Juan donde aparecen extremidades y una cabeza sobresaliendo de la orla geométrica. Sobre la obra ver: MeEhAN, B., The Book of Kells: an illustrated introduction to the manuscript in Trinity College Dublin, Thames and Hudson, Londres, 1994, $1^{\text {a }}$ ed.

${ }^{15}$ En opinión de Martínez de Aguirre se trataría de una representación del pater familias: MARTínEZ DE AGUIRRE AlDAZ, J, «En torno a la», p. 10.

${ }^{16}$ L'ENGLE, Susan, GiBBS, R., Iluminating the Law, p. 70.

${ }^{17}$ LADNER, G. B., «Medieval and Modern», pp. 244-245.

${ }^{18}$ Un ejemplo de ello: RAH, códice 25. Vid: MARTínEZ De AGUIRRE ALDAZ, J., «En torno a la», p. 10.
} 


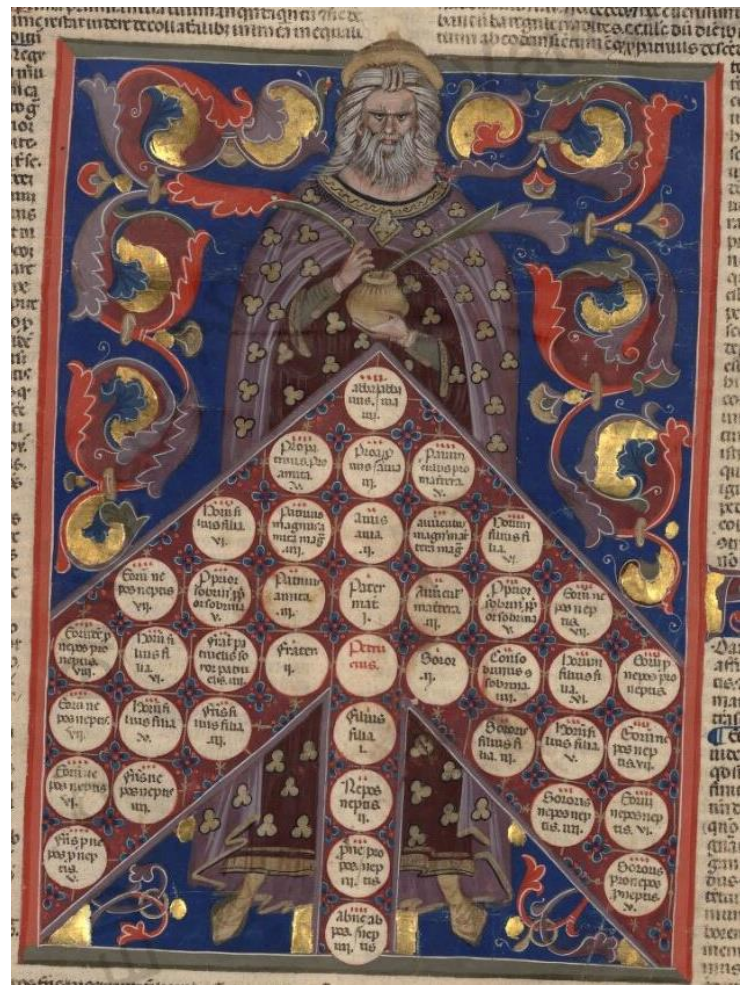

Figura 2. Árbol de consanguinidad antropomorfo de un ejemplar italiano boloñés del siglo XIV de las Decretales de Gregorio IX.

BAV, Mss. Borgh. 372, 3v.

El grupo arquitectónico, menos corriente que los anteriores, responde a la adopción de elementos arquitectónicos (generalmente arquerías, torres y techumbres) como enmarcado de las distintas escenas, esquema compositivo habitual en los manuscritos europeos medievales. Los árboles de este tipo encierran los diversos grados de parentesco en formas arqueadas con terminaciones de torres, ventanales o techumbres. Un ejemplo de ello sería el Cod. inv. 27 de la Biblioteca de Göttingen.

Finalmente, el grupo mixto es la combinación de dos esquemas distintos en uno: el árbol de consanguinidad y el árbol de afinidad. Estos esquemas, muy corrientes a partir del siglo XIII, adoptan la forma de $\mathrm{T}$ con círculos con los grados de parentesco (Fig. 3). Además, estos árboles presentan siempre unas filacterias en los círculos superiores donde aparece escrito si existe prohibición o no de contraer matrimonio con el grado correspondiente. Los árboles de afinidad pueden ser antropomórficos, pero en contra de la figura masculina que suele aparecer en los árboles de consanguinidad, en estos casos aparece una pareja, haciendo referencia al objetivo de estas composiciones ${ }^{19}$. También es muy recurrente que aparezca Cristo Maiestas Domini o Cristo juez.

\footnotetext{
${ }^{19}$ L'EngLe, S., GiBBS, R., Iluminating the Law, p. 71.
} 


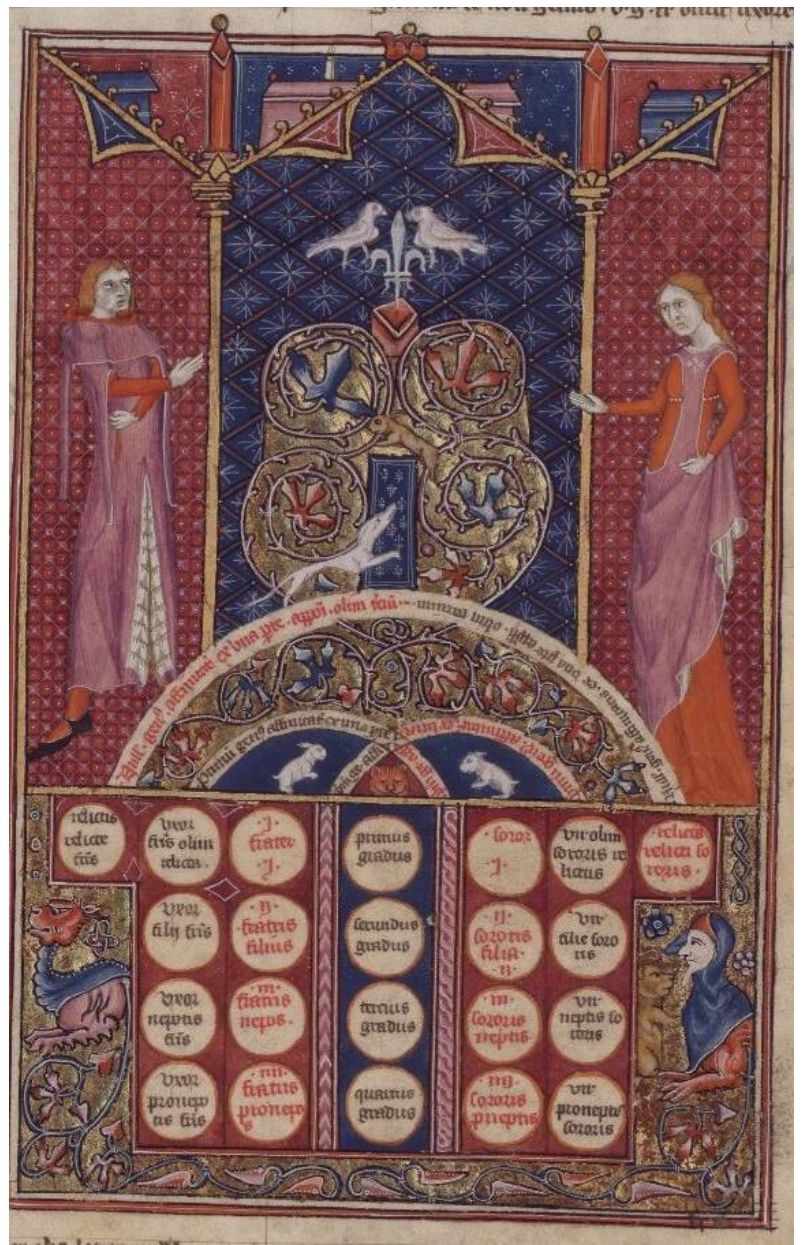

Figura 3. Árbol de Afinidad con pareja de un ejemplar francés de las Decretales de Gregorio IX, BAV, Vat. Lat. 1390, f. 212r.

En los cánones del IV Concilio de Letrán se estableció la prohibición de contraer matrimonio hasta el cuarto grado de parentesco, por ello todos los manuscritos que son posteriores a la fecha del concilio (1216) siempre plasman árboles con los cuatro grados de parentesco. Los manuscritos anteriores al concilio sí pueden mostrar distintas variantes en cuanto al número de grados: por ejemplo, el manuscrito Pal. Lat. 625 de la Biblioteca Apostólica Vaticana muestra hasta cuatro variantes de árboles de consanguinidad y afinidad con tres, cuatro o hasta siete grados (folios 1v-4r).

\section{LOS ÁRBOLES DE CONSANGUINIDAD Y AFINIDAD EN LAS SIETE PARTIDAS}

Las Siete Partidas, obra principal de las producciones jurídicas del scriptorium de Alfonso X el Sabio y, obra central y clave en la historia del derecho en los reinos hispanos por su destacada importancia, también regularon los diversos modos y grados de parentescos. En la Cuarta Partida, cuyo texto analiza las relaciones conyugales («Quarta Partida que fabla de los desposorios et casamientos»), el título VI regula los diversos 
grados de parentesco. En la ley II se define qué es la línea de parentesco y cuántas existen, estableciendo que la línea es «ayuntamiento ordenado de personas que se tienen vnas con otras como cadenas descendiendo de vna rayz, et facen entre si grados departidos» ${ }^{20}$. En esta ley se aboga por representar gráficamente las diferentes líneas de parentesco con objeto de que mediante la imagen se explique mejor el contenido que aparecerá en las dos leyes siguientes:

«Et porque algunos dubdarian ó non entendieren este encadenamiento en estos grados, amenos de los ver por vista, touvimos por bien fazer pintar el arbol que lo demuestra abiertamente, e poner le en este libro, por que los omes lo entiendan mejor. Ca las cosas que los omes veen, mas de ligero las aprenden, que las otras que han de aprender por oyda» ${ }^{21}$.

De este modo, queda legitimado el uso gráfico del árbol de consanguinidad como herramienta útil de comprensión del texto que alcanzará un mayor desarrollo en las leyes siguientes. Así en la ley III se describe qué es el parentesco y cuántas formas hay de tener en cuenta los grados: «segunt fuero de los legos», es decir, el derecho civil o romano; y «segunt establecimiento de la sancta iglesia», es decir, según el derecho canónico. De este modo, para el «fuero de los legos» los hijos conforman el segundo grado mientras que para el derecho canónico los hijos conforman el primer grado. El texto de la ley distingue así el uso del primero, destinado para los heredamientos en los casos en que no haya testamento, y del segundo, que tiene que ver con los desposorios. Finalmente, en la Ley IV, se describen los cuatro grados de parentesco según el derecho canónico y hasta qué momento no se permite el matrimonio. El árbol aparece justamente después de la ley II, en un espacio que se deja para que un iluminador ejecute la composición. No obstante, en algunos casos el árbol aparece al terminar la ley IV, que es la ley que describe los cuatro grados de consanguinidad, en este caso con objeto de que la comprensión de la información se produzca tras haber leído el texto.

No todos los manuscritos de la Cuarta Partida contienen imágenes de árboles de consanguinidad, de hecho, este motivo solo está presente en dos manuscritos, aunque existe la constancia de que estuvo al menos planificado en un tercero. No parece que haya un motivo claro sobre la razón de que un elemento icónico tan distinguido solamente aparezca en un par de manuscritos. Hay que tener en cuenta que, de todos los códices y fragmentos del código alfonsí, los ejemplares de la Cuarta Partida son los menos numerosos: hay al menos nueve manuscritos conocidos frente al resto de partidas que superan los diez códices, algunos incluso la veintena como la Segunda Partida. Probablemente la escasez de manuscritos de la Cuarta Partida sea una causa que explique que no hayan sobrevivido más árboles de consanguinidad, pero también hay que resaltar

\footnotetext{
${ }^{20}$ Cuarta Partida, Título VI, Ley II. Alfonso X, Las Siete Partidas glosadas por el licenciado Gregorio López, Boletín Oficial del Estado, Madrid, 1985, $1^{\text {a }}$ ed., t. 2, p. 16

${ }^{21}$ Alfonso X, Las Siete Partidas, pp. 16-17. Esta premisa del uso pedagógico de la imagen utilizada como recurso informativo que complemente el escrito es una constante en el scriptorium alfonsí. Véase FERNÁNDEZ FERNÁNDEZ, L., Arte y Ciencia en el scriptorium de Alfonso X, Universidad de Sevilla- Cátedra Alfonso X, Sevilla, 2013, $1^{\text {a }}$ ed., pp. 242-243.
} 
que el corpus ilustrativo de las Partidas no es homogéneo ni está codificado como sí ocurre con otras obras legales (Decretales, Decreto, Digesto, etc.). De hecho, varía mucho en función del tipo de manuscrito, su material, mecenazgo o su utilidad (existen manuscritos de cierto lujo vinculados a mecenazgo nobiliario, pero también hay manuscritos escritos en papel de calidad menor realizados a expensas de un productor menos notable). Estas son algunas causas que explican la falta de estudios sobre la iluminación de las Siete Partidas ${ }^{22}$.

Como ya he indicado, existen árboles de consanguinidad en un par de ejemplares y el manuscrito Z-I-15 de la Real Biblioteca del Monasterio de El Escorial es el primero de estos. Es un códice facticio que recoge dos manuscritos distintos, uno del siglo XIV y otro del XV, con los textos de la Tercera y Cuarta Partidas, y que fue utilizado para la edición de la Real Academia de la Historia, siendo el denominado Escurialense $3^{\circ}$. El manuscrito es de pergamino, aunque con dos calidades distintas, y está escrito en letra gótica libraria de privilegios, la Tercera Partida, y gótica redonda libraria del siglo XV, la Cuarta. Ambos manuscritos presentan iluminación, si bien el primero es meramente ornamental en letras capitales (de tipo de filigrana), mientras que en el segundo hay mayor variedad de motivos: iniciales vegetales polícromas, orlas vegetales polícromas, iniciales de filigrana, etc. Es precisamente el árbol de consanguinidad que presenta este manuscrito el elemento pictórico más destacado del mismo, ocupando los folios $188 \mathrm{v}$ y 189r del códice. Está formado por dos esquemas arbóreos, semejantes, pero con algunas diferencias. Estos árboles muestran las líneas ascendentes, descendentes y traviesas de los grados de parentesco.

Ambas composiciones recogen de forma abundante las tres líneas y los diversos grados: ascendente: padre, abuelo, bisabuelo, trasvuelo; descendiente: hijo, nieto, bisnieto y trasbisnieto; y traviesa o paralela: hermano, hijos de los hermanos, nietos de los hermanos y bisnietos de los hermanos. No obstante, el primero de ellos amplía los grados de cuatro a seis, de este modo en la línea ascendiente se recoge hasta el quinto abuelo, y en la descendiente hasta el quinto nieto. El segundo de ellos solo recoge los cuatro grados prescriptivos.

Estas dos composiciones toman la forma arbórea esquematizada en forma de flecha en la que los descendientes ocupan el tronco del árbol y los ascendientes la copa. Así la línea descendiente conforma el tronco del árbol, la ascendente sube hasta la copa del árbol, y las traviesas son las que dan forma al mismo, generando un perfil de flecha al ser estas líneas oblicuas al tronco principal. Los grados se inscriben en círculos blancos y remarcados por tinta azul y roja, en alternancia; además, los círculos quedan unidos entre sí en una red de losanges dorados usando también tinta roja y azul. El árbol se flanquea con dos figuras híbridas con torso humano y con garras de león, únicas en toda la iluminación del códice. Existe una diferencia más en la composición de estos

\footnotetext{
${ }^{22}$ Lo expuesto en este párrafo es objeto de estudio en mi tesis doctoral en curso titulada «A servicio de Dios y por comunal de todos hacemos este libro». Análisis y contexto de la iluminación de los manuscritos de las Siete Partidas y dirigida por la doctora Laura Fernández Fernández.
} 
dos árboles, y es que el segundo no crea una trama homogénea de losanges, sino que las líneas oblicuas están iluminadas en oro y azul, por lo que el efecto final es el de simular ramas que salen del tronco principal del árbol. Además de las figuras antropomorfas, lo más destacado es la decoración vegetal consistente en hojas bícromas y grandes flores que ocupan el mayor espacio vacío del árbol.

El primero de estos árboles (Fig. 4) recoge seis grados de parentesco porque está reflejando, como ya he indicado con anterioridad, las reglas de parentesco según el derecho romano, el cual concibe que hay parentesco hasta el sexto grado. El otro árbol, sin embargo, recoge solo cuatro grados porque está tomando las reglas del derecho canónico tras los cánones del IV Concilio de Letrán que redujo la concepción de parentesco al cuarto grado. Los árboles, de este modo, no hacen más que plasmar las dos variantes de árboles consagrados en la ya citada ley III de este título de la Cuarta Partida.

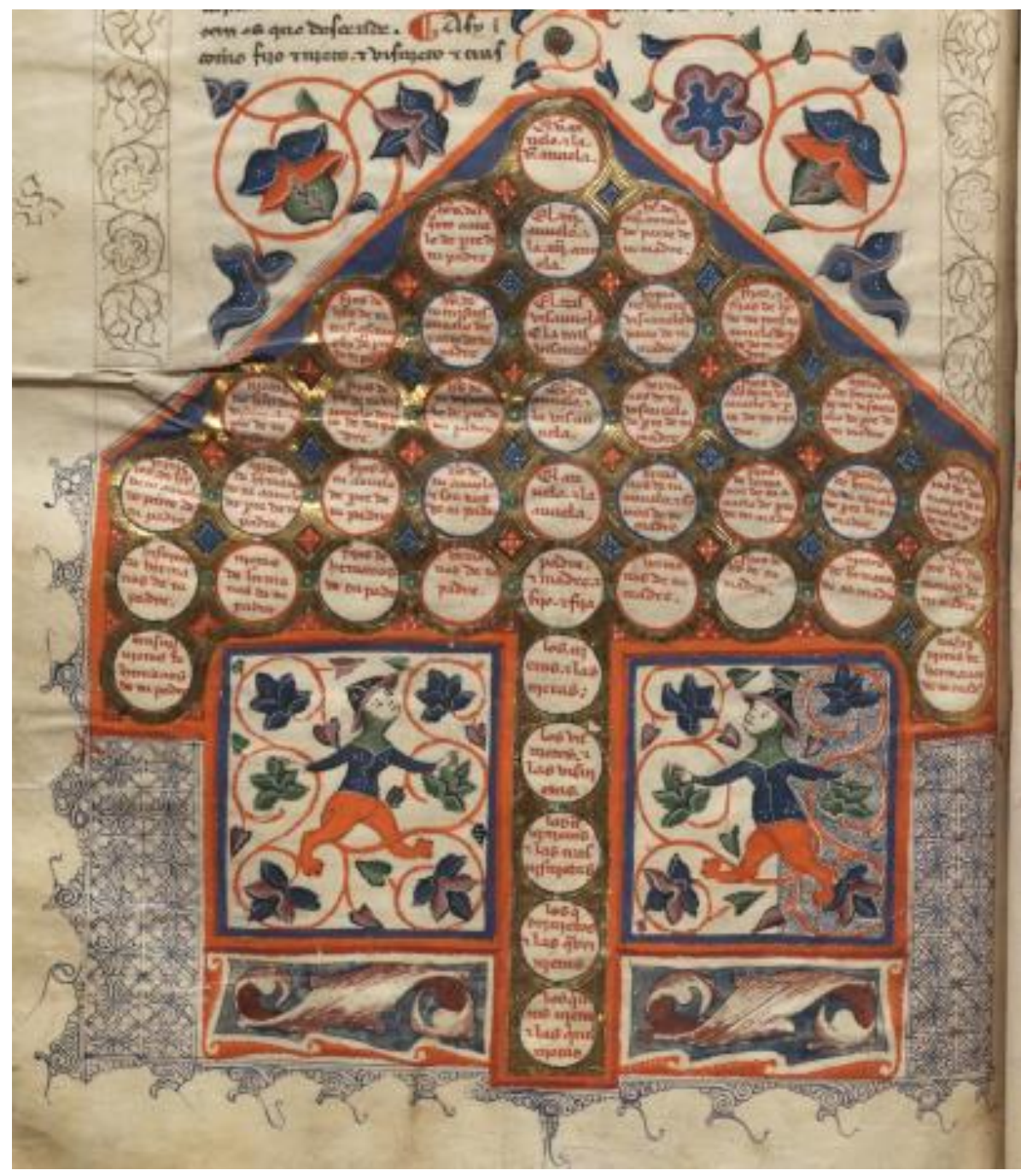

Figura 4. Árbol de consanguinidad «segunt fuero de legos». RBME, Mss. Z-I-15, f. 188v. (C) Patrimonio Nacional 
Además de estos árboles de consanguinidad, esta copia de la Cuarta Partida incluye un árbol de afinidad, otro de los esquemas compositivos más frecuentes de los manuscritos jurídicos medievales. Estos árboles, relacionados con los de consanguinidad, muestran también los cuatro grados de parentesco, pero están referidos a las relaciones entre el hombre y la mujer, en lo que a permisividad del matrimonio se refiere. Este árbol viene a simplificar la información contenida en la Ley $\mathrm{V}$ de este mismo título que es la que regula la afinidad y la cuñadía (Fig. 5). Responde a una forma en «T» cuyo núcleo principal son los cuatro grados de parentesco encerrados en círculos, y flanqueando estas dos filas por cada lado con las diversas personas. En la parte superior dos filacterias señalan entre sí qué grados poseen afinidad o cuñadía, por lo que tienen prohibición de contraer matrimonio. Tal y como se puede observar responde a los mismos motivos decorativos que los vistos para los árboles de consanguinidad, una iluminación que probablemente sea castellana, con presencia de decoración en forma de filigrana azul en los laterales inferiores del primer árbol y que no es de excesiva calidad, utilizando además algunos elementos propios de la tradición francesa como los fondos planos geométricos azulados.

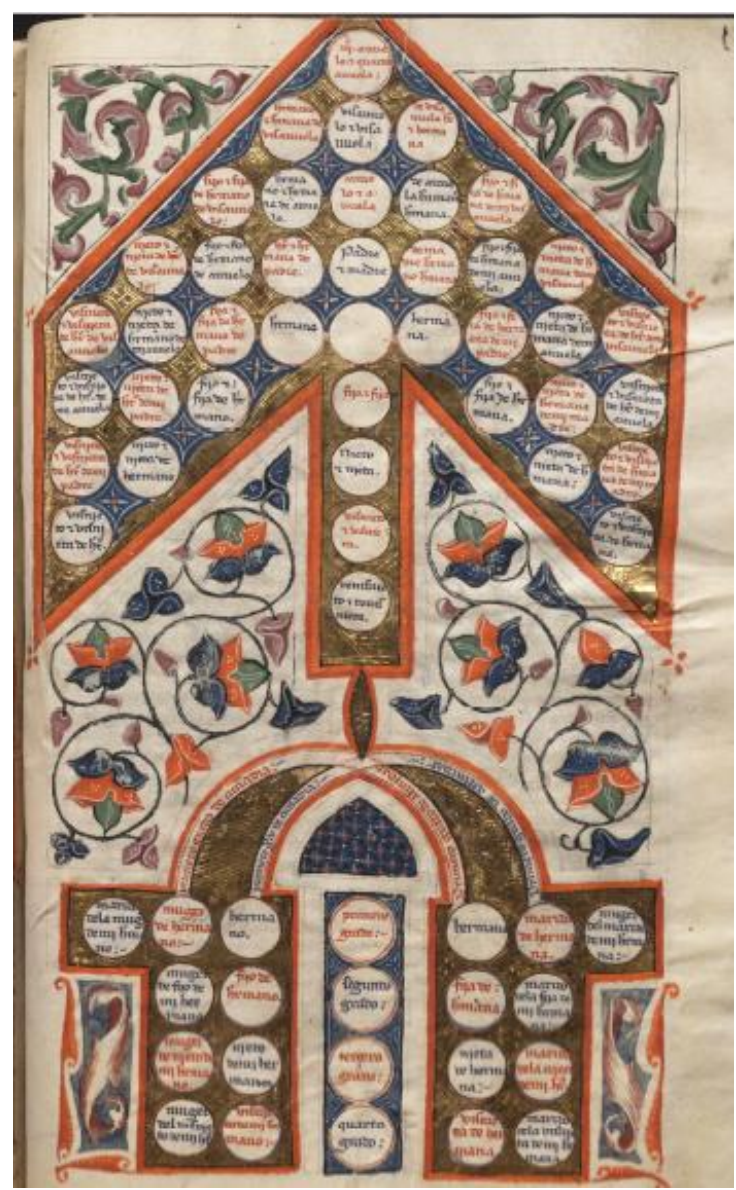

Figura 5. Árbol de consanguinidad y afinidad «segunt establecimiento de la sancta iglesia». RBME, Mss. Z-I-15, fol. 189r. (C) Patrimonio Nacional 
El otro manuscrito que presenta un árbol de consanguinidad es el Mss. 43-15 de la Biblioteca Capitular de la Catedral de Toledo (Fig. 6). Este manuscrito recoge el texto de la Cuarta Partida, escrito en papel en letra de privilegios del siglo XIV. A diferencia del anterior, la iluminación del mismo es muy pobre, ya que únicamente se decoran las iniciales con motivos de filigrana negra y roja, con un tratamiento muy tosco. El árbol de consanguinidad aparece en el folio 20r, justo al terminar el texto de la Ley II del Título VI señalado por una rúbrica previa «El arbol a de estar a q pintado». que indica el espacio donde debía aparecer el árbol, que finalmente sí se llegó a realizar.

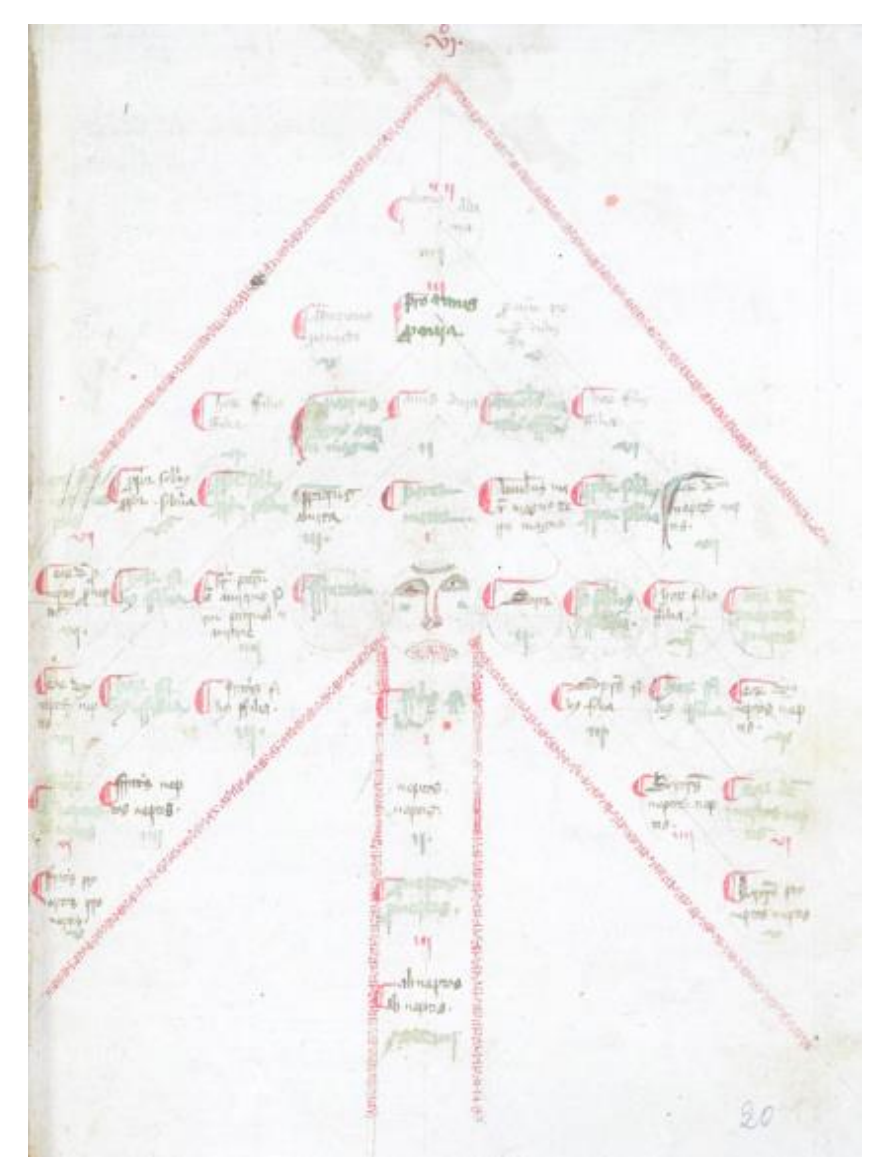

Figura 6. Árbol de consanguinidad,

Biblioteca Capitular de Toledo, Mss. 43-15, fol. 20r.

El árbol toma la forma de composición arbórea en flecha, encerrando los conceptos en círculos unidos mediante líneas que no se debieron terminar. La iluminación es paupérrima: solo se remarcan los círculos y la forma general del árbol usando pequeñas líneas en tinta roja. El círculo central, que es una representación de la persona, contiene un rostro muy esquemático y algo tosco. A diferencia del árbol del manuscrito escurialense, este manuscrito contiene los términos en latín, no en castellano y, además, señala mediante numerales romanos cada uno de los grados. Este diagrama solamente recoge el parentesco según el derecho canónico, con los cuatro grados. Debido a la sencillez 
icónica y precariedad estilística del presente manuscrito, es muy posible que fuera realizado en un entorno social menos pudiente o quizá una copia interna para un manuscrito posterior.

Junto a estos dos ejemplos de árboles de consanguinidad hay que señalar que el Mss. 43-16, también de la biblioteca capitular toledana, previó el uso de un árbol gráfico pero que nunca se llegó a terminar. Es un manuscrito también de la Cuarta Partida, fechable en el siglo XIV, en papel, escrito en letra de privilegios cursiva, donde la única decoración existente son rasgueos blancos en las letras iniciales rojas. Este árbol, como el del ejemplar anterior, estaba diseñado para aparecer justo después del texto de la Ley II del Título VI, pero nunca se llegó a realizar. El folio 10v, donde tendría que haberse realizado, aparece prácticamente en blanco. Podemos saber que ese espacio estuvo destinado al árbol de consanguinidad por la presencia de una anotación en el margen superior remarcado donde se lee «Espacio para el arbol fazer». Lamentablemente no se llegó a ejecutar quedando vacía la plana del folio destinada a tal efecto (Fig. 7).

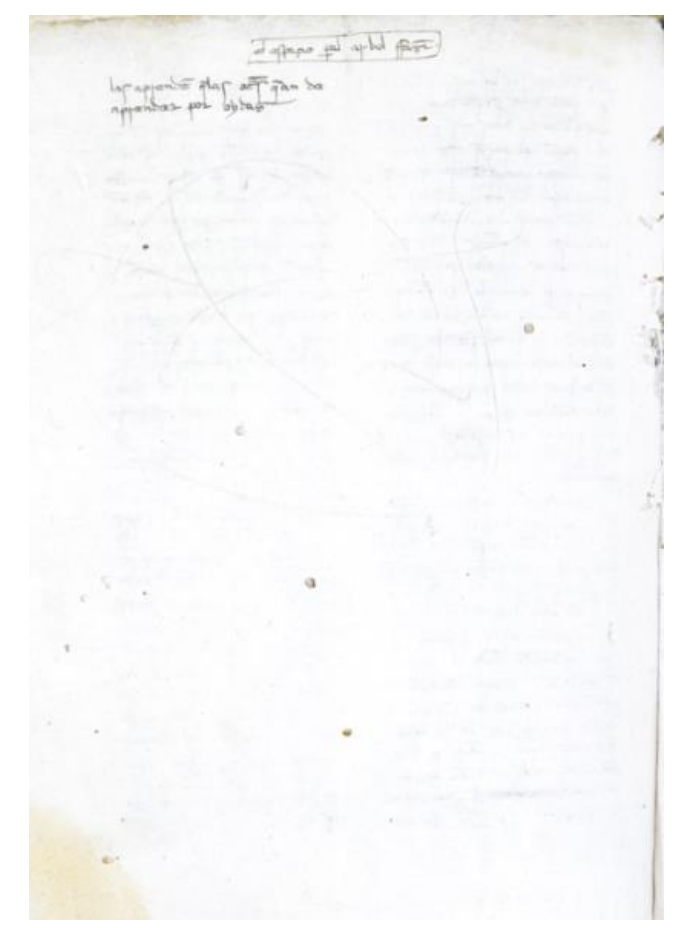

Figura 7. Folio en blanco para un árbol nunca realizado.

Biblioteca Capitular de Toledo, Mss. 43-16, fol. 10v.

En lo tocante a su correspondencia con otros árboles en obras medievales hispanas antes citadas (Beatos, Etimologías), los ejemplos de las Partidas guardan una cercanía iconográfica más próxima a las composiciones del Decreto y las Decretales, donde la forma arbórea antropomorfa está asentada y no hay apenas composiciones geométricas ni cruciformes. Sin embargo, los manuscritos de las Partidas contienen unos árboles 
bastante simples y escuetos sin una presencia de figuración notable. Como son los únicos vestigios, al menos hoy en día conocidos, de esta iconografía en las Siete Partidas resulta complicado establecer si en el caso de las Partidas se intentó dar primacía al texto evitando incorporar excesiva figuración. ¿Los códices de la Cámara Regia ${ }^{23}$ pudieron contener árboles más complejos? De momento es una incógnita, aunque existe esa posibilidad.

Las reglas de consanguinidad también están presentes en el Fuero Juzgo y hay ciertos manuscritos que sí han ilustrado dichas reglas con un árbol, de hecho, hay un caso muy paradigmático y con cierta relación con las obras alfonsíes: el mss. VITR/17/10 de la BNE. Es un manuscrito del Fuero Juzgo ${ }^{24}$ que presenta un árbol de consanguinidad interesante iconográficamente ya que queda fusionado con otro diagrama arbóreo genealógico como es el árbol de Jesé (Fig. 8). No es un árbol de Jesé propiamente dicho, ya que no aparece representada la genealogía de Cristo, sino que es un árbol de consanguinidad antropomorfo con la figura de Jesé recostado en su raíz. El iluminador introdujo así un elemento de originalidad a la composición, vinculando la iconografía del árbol de consanguinidad con esta iconografía religiosa que tiene en común la transmisión de la herencia. En lo tocante al estilo, es una iconografía que está relacionada con la tradición pictórica del scriptorium alfonsí ya que incorpora la orla floral con las armas reales de Castilla y León presente en códices de las Cantigas de Santa María y la General Estoria ${ }^{25}$. No obstante, la escritura del códice dista mucho de la escritura empleada en estos códices alfonsíes y parece ser del siglo XIV, por lo que es posible que sea una copia posterior del Fuero Juzgo que incorpora una iluminación que imita el estilo alfonsí. ¿Podrían haber existido códices más antiguos de las Siete Partidas con árboles de consanguinidad semejante a este manuscrito? Es una posibilidad, pero es arriesgado presentar esa relación cuando no han llegado hasta nosotros muchos de los códices de las Partidas. En lo que sí se puede comparar es que en este ejemplar

\footnotetext{
${ }^{23}$ No existen apenas manuscritos de las Partidas contemporáneos a Alfonso X, de hecho, la gran mayoría de manuscritos son copias tardías de los siglos XIV y XV, a excepción del Add. ms. 20787 de la British Library que es el más cercano cronológicamente al Rey Sabio. La historiografía de las Siete Partidas ha incidido en muchas ocasiones a la falta o destrucción de estos ejemplares mediante distintas hipótesis aún no bien resueltas. Sobre el estado de la cuestión ver: SÁNCHEZ-ARCILLA BERNAL, J. A., «La obra legislativa de Alfonso X. Historia de una polémica», DomíngueZ RodríGuEZ, A.; MonTOYA MarTíneZ, J., El Scriptorium alfonsí: de los libros de Astrología a las Cantigas de Santa María, Editorial Complutense, Madrid, 1999, $1^{\text {a }}$ ed., pp. 17-81.

${ }^{24}$ El libro III del Fuero Juzgo dedica un título sobre los grados de parentesco, pero no señala que se puedan realizar árboles pictóricos a diferencia del texto de Partidas. Sobre el manuscrito ver DOMíNGUEZ RODRÍGUEZ, A., «El "Officium Salomonis” de Carlos V en el monasterio de El Escorial: Alfonso X y el planeta Sol. Absolutismo monárquico y hermetismo», Reales Sitios, 22, (1985), pp. 11-88. DomínGUEZ RodríGueZ, A., «Fuero Juzgo», Alfonso X El Sabio: Sala San Esteban, Murcia, 27 octubre 2009-31 enero 2010, Isidro Bango Torviso (dir.), Ayuntamiento de Murcia, Murcia, 2009, $1^{\text {a }}$ ed., pp. 510-511. Rodríguez PORTO, R. M., Thesaurum: la Crónica Troyana de Alfonso XI (Escorial, h.I.6) y los libros iluminados de la monarquía castellana (1284-1369), tesis doctoral, Universidad de Santiago de Compostela, Santiago de Compostela, 2012, t. 2, pp. 173-213.

${ }^{25}$ De los códices de las Cantigas estoy refiriéndome a los manuscritos T-I-1 de la RBME y B.R.20 de la Biblioteca Nacional Central de Florencia. En lo tocante al códice de la General Estoria me refiero al manuscrito Urb.Lat. 539 de la BAV.
} 
del Fuero Juzgo se está utilizando un árbol de seis grados como también aparece en el manuscrito escurialense Z-I-5, precisamente porque el Fuero Juzgo es una versión al romance del Liber Iudiciorum visigodo, por tanto, muy anterior al concilio lateranense.

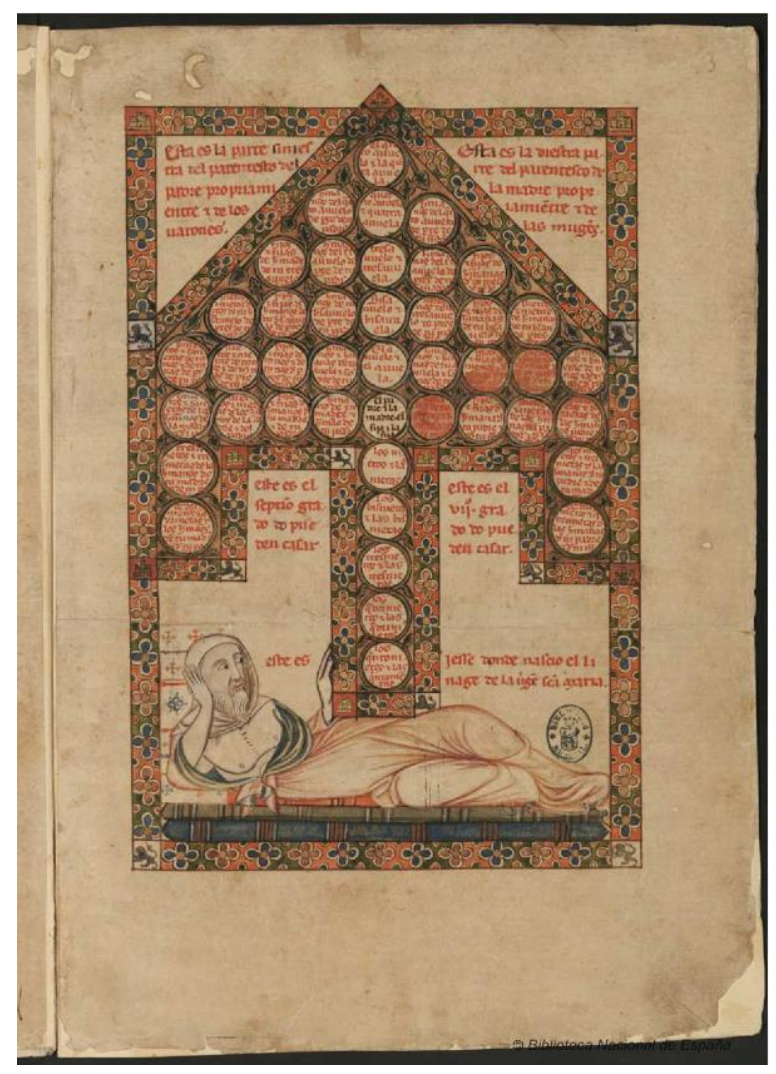

Figura 8. Árbol de consanguinidad con Jesé en un ejemplar del Fuero Juzgo. BNE, MSS/VITR/17/10, f. 3r.

Por último, los árboles de consanguinidad en las Siete Partidas no aparecieron únicamente en los ejemplares manuscritos, sino también en las versiones impresas, ya que la edición de Gregorio López de 1555 contempló la inclusión de árboles de consanguinidad y afinidad (Figs. 9 y 10). De este modo, junto al Título VI se desarrollaron dos estampas con los diagramas de los distintos árboles de consanguinidad y afinidad. En este caso, los árboles presentan una forma arquitectónica de estilo renacentista rematada con un frontón curvo y con decoración de grutescos. Este diseño fue renovado en la reedición de 1789, con un diseño arbóreo vegetal más naturalista (Figs. 11 y 12) ${ }^{26}$.

\footnotetext{
${ }^{26}$ Alfonso X, Las Siete Partidas de Don Alfonso el Sabio glosadas por el licenciado Gregorio López del Consejo Real de Indias de S. M., Oficina de Benito Cano, Madrid, 1789, t. 2.
} 


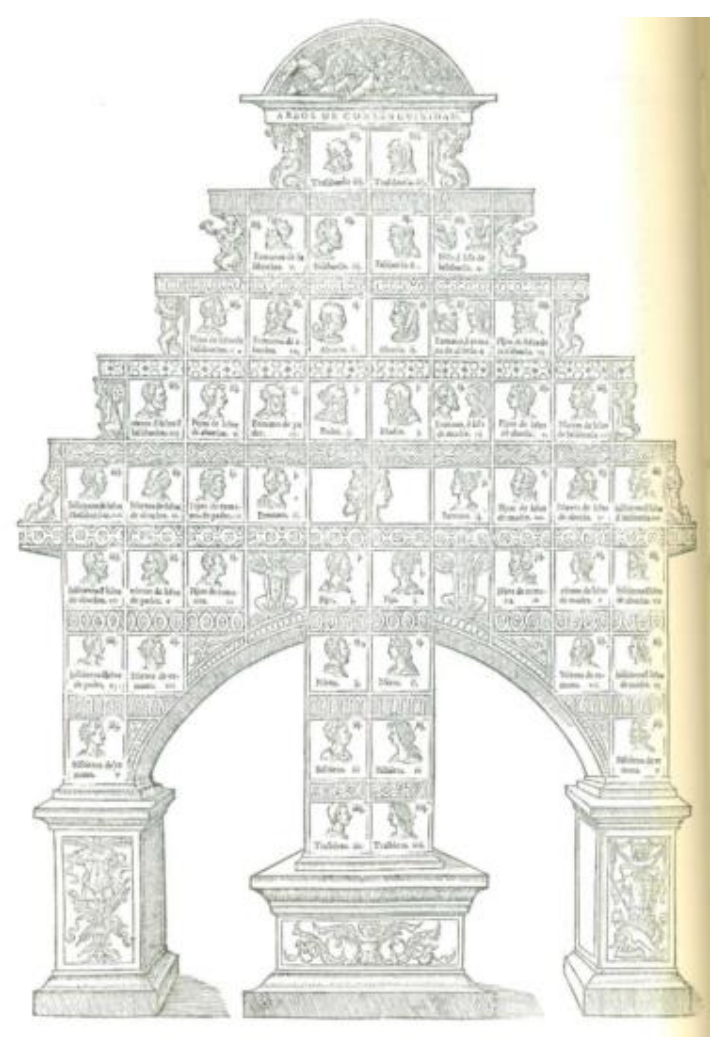

Figura 9. Árbol de consanguinidad arquitectónico.

Edición de Gregorio López de 1555, p. 18.

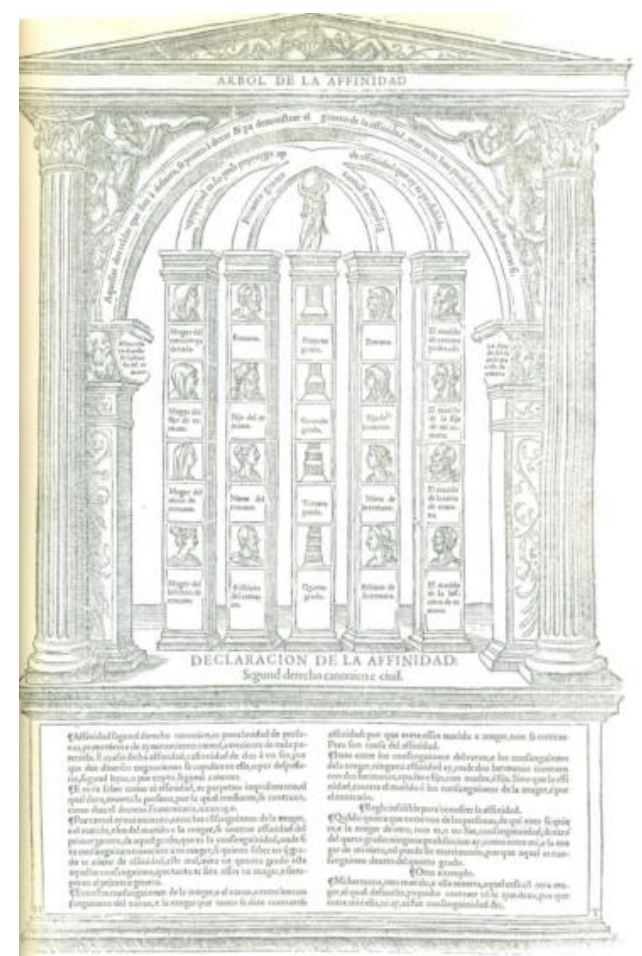

Figura 10. Árbol de afinidad arquitectónico.

Edición de Gregorio López de 1555, p. 19. 


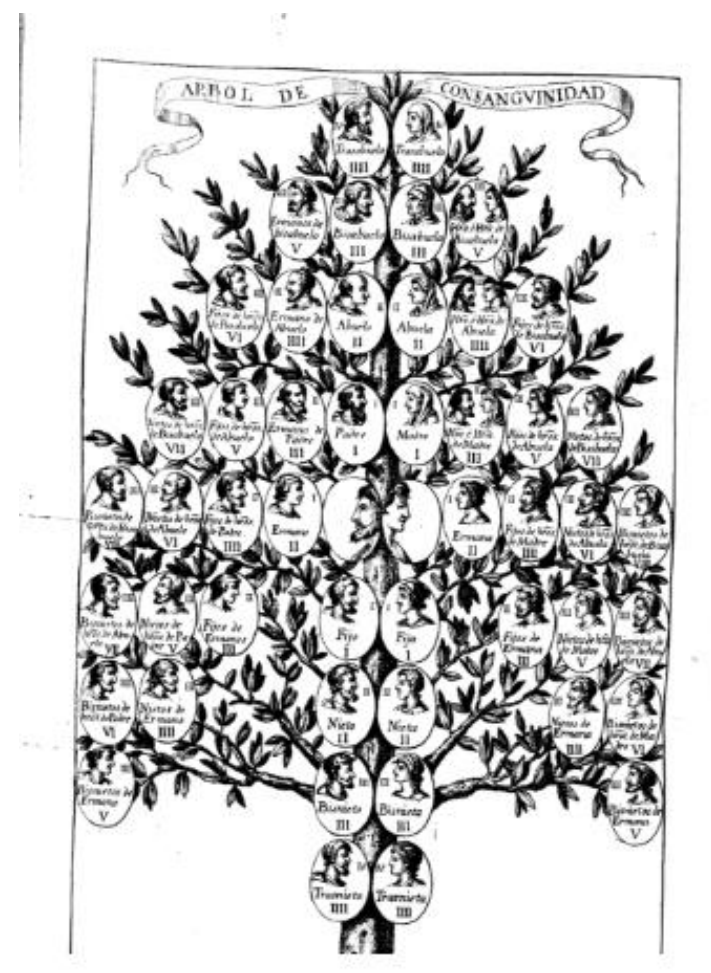

Figura 11. Árbol de consanguinidad.

Edición de Edición de Gregorio López de 1789, p. 491.

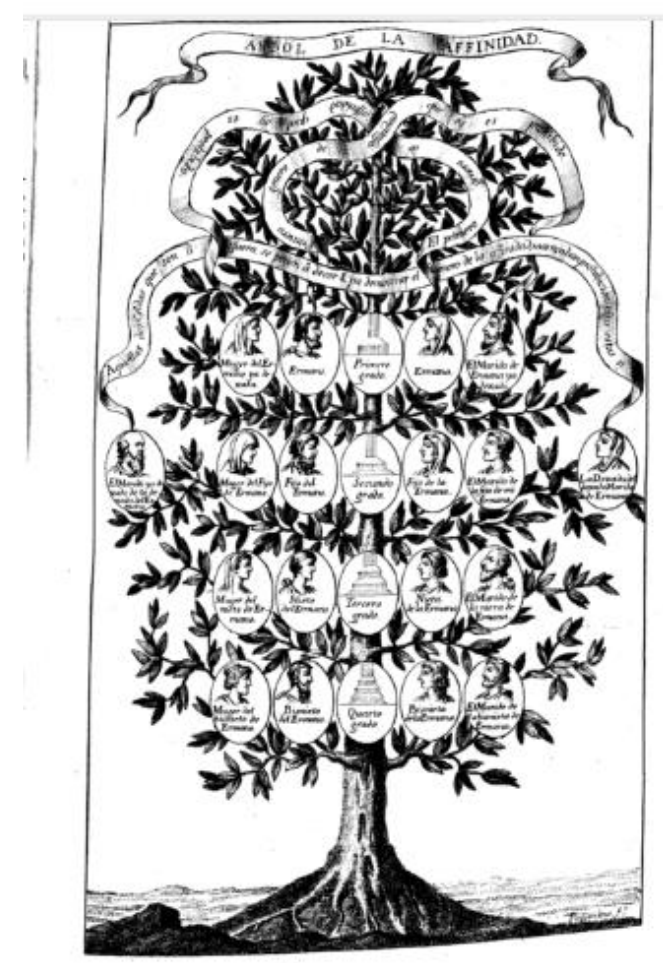

Figura 12. Árbol de afinidad.

Edición de Gregorio López de 1789, p. 494. 


\section{CONCLUSIÓN}

La presencia de árboles de consanguinidad en las Siete Partidas no supuso un elemento novedoso en lo que respecta a la iluminación de manuscritos jurídicos, ya que, como he señalado anteriormente, es un elemento iconográfico antiguo que hunde sus raíces en varias obras jurídicas altomedievales. En el territorio hispano aparece también en otro tipo de obras como las Etimologías de San Isidoro, algunos Beatos e incluso en algunas copias del Fuero Juzgo. En lo que respecta a las Siete Partidas la importancia de los árboles de consanguinidad viene reflejada por el hecho de que el texto de las Partidas ya preveía la inclusión de árboles iluminados con el objetivo de que la claridad de los conceptos fuera mayor. Este uso del elemento gráfico como apoyo al texto de la ley entronca muy bien con el modo en que las Siete Partidas utilizan elementos para lograr una mayor comprensión del contenido: ya sean traducciones al romance de términos latinos, ya sean citas de autores clásicos, etc., y en general con el planteamiento explicativo presente en toda la producción alfonsí. Esto hace que el árbol no sea un elemento ornamental, sino un elemento destacado dentro del discurso normativo del texto. Finalmente, pese a ser una iconografía importante y que ha tenido su proyección a ediciones impresas, hay pocas muestras de esta iluminación en los manuscritos, ya que, probablemente, sea producto de la pérdida de códices de la Cuarta Partida. 